\title{
Genes Encoding Enzymatic Activities Implicated in the Eicosanoid Cascade of Arachidonic Acid and their Receptors are Expressed at mRNA Levels in Human Meningiomas
}

\author{
Rafael De Armas ${ }^{1,3}$, Karine Durand ${ }^{1}$, Nicolas Weinbreck', Sandrine Robert ${ }^{1}$, \\ Jean-Jacques Moreau ${ }^{2}$, Matias Pebet ${ }^{3}$, François Labrousse ${ }^{1}$ and Yves Denizot $^{4 *}$ \\ ${ }^{1}$ Service d'Anatomie Pathologique, CHU Dupuytren, Limoges, France \\ ${ }^{2}$ Service de Neurochirurgie, CHU Dupuytren, Limoges, France \\ ${ }^{3}$ Hospital de Clinicas, Instituto de Neurologia, Montevideo, Uruguay
}

${ }^{4}$ UMR CNRS 6101, Centre National de la Recherche Scientifique, Université de Limoges, France

\begin{abstract}
In view of the important oncogenic action of lipoxygenase (LOX) and cycloxygenase (COX) enzymatic activities we investigated, by using real time PCR, their presence in human meningiomas. Results indicated the presence of 5-LOX, 12-LOX, 15-LOX1, 15-LOX2, COX-1, COX-2, prostaglandin E (PGE) synthase, prostacyclin (PGI) synthase and thromboxane (TX) synthase transcripts in meningiomas but without relation to the tumor grade, the subtype of meningiomas, the presence of inflammatory infiltrated cells, of an associated edema, mitosis, brain invasion, vascularisation or necrosis. Similar results were found for BLT1 and BLT2 transcripts (encoding LTB4 receptors) and for prostanoid receptor transcripts $\left(\mathrm{EP}_{1-4}\right.$ for $\mathrm{PGE}_{2}$, IP for $\mathrm{PGI}_{2}$ and TP for $\mathrm{TXA}_{2}$ ). In conclusion, genes encoding enzymatic activities implicated in the eicosanoid cascade are expressed in meningiomas. LOX- and COX-derived arachidonic acid metabolites might act on tumor growth not only by acting on cell growth but also by altering the local cytokine and/ or angiogenic networks.
\end{abstract}

Keywords: Meningiomas; Lipoxygenase; Cyclooxygenase; Prostanoid receptors; Arachidonic acid metabolites

\section{Introduction}

Meningiomas present clinically by causing focal or generalized seizure disorders, focal neurological deficits or neuropsychological decline (Whittle et al., 2004). Lipid mediators such as platelet-activating factor (PAF) and eicosanoids have been reported to act on the growth of various cell types (Dupuis et al., 1997a, b). A possible role for PAF has been reported in human meningiomas (Denizot et al., 2006). A role for the whole eicosanoid cascade has been suggested in meningiomas (Nathoo et al., 2004). Eicosanoids are a large family of lipid mediators with potent inflammatory and oncogenic properties. They are produced by two enzymes classes, lipoxygenases (LOX) and cyclooxygenases (COX). The LOX pathway acts on arachidonic acid (AA) to generate $\mathrm{LTB}_{4}, 12$-HETE and 15 -HETE by 5-LOX, 12-LOX and 15-LOX activities, respectively (Kuhn et al., 2002; Radmark, 2002; Yoshimoto and Takahashi, 2002). A 12S-LOX and 12R-LOX were reported. A 15-LOX1 and 15-LOX2 have been identified. Whether receptors for 12-LOX and 15-LOX metabolites are not cloned, two receptors for $\mathrm{LTB}_{4}$ have been identified: BLT1 and BLT2. The COX pathway involves the conversion of AA to $\mathrm{PGH}_{2}$ (Cipollone et al., 2008). The profile of products made by cells expressing COX-1 (constitutive enzyme) or COX-2 (inducible enzyme) is therefore determined by the presence of different cell-specific downstream enzymes. $\mathrm{PGH}_{2}$ leads to generation of prostanoids, which include prostaglandin $\mathrm{E}_{2}$ (via a PGE synthase), thromboxane $\mathrm{A}_{2}$ (via a thromboxane synthase, TX synthase) and prostacyclin (via a prostacyclin synthase, $\mathrm{PGI}_{2}$ synthase). Effects of the prostanoid release are mediated by prostanoid receptors on target cells and tissues. These correspond to each of the COX metabolites: $\mathrm{EP}_{1-4}$ for $\mathrm{PGE}_{2}$, IP for $\mathrm{PGI}_{2}$ and $\mathrm{TP}$ for $\mathrm{TXA}_{2}$.

The existence of COX and 5-LOX enzymes and high levels of AA in meningiomas create a favorable environment for the efficient production of eicosanoids (Boado et al., 1992; Nathoo et al., 2004; Pfister et al., 2007). Thus $\mathrm{TXB}_{2}, \mathrm{PGE}_{2}$ and $\mathrm{PGI}_{2}$ are produced in meningiomas (Castelli et al., 1989). Nevertheless many important questions remain unanswered. Little is known about the expression of prostanoid and $\mathrm{LTB}_{4}$ receptors in meningiomas. Little is known about their expression of 12-LOX and 15-LOX. Little is known about the relationships between tumor LOX, COX and downstream enzymes with respect to the tumor grade. In view of the potentially important oncogenic actions of eicosanoids in human meningiomas, real time polymerase chain reaction (PCR) was utilized to quantify transcripts for the enzymatic activities implicated in the eicosanoid cascade and their receptors in intracranial meningiomas.

\section{Patients and Methods}

\section{Patients}

The procedure of the present study followed the rules edited by the French National Ethics. Ethics approval was obtained from the ethics committee of our hospital (CHU Dupuytren, Limoges, France). Twenty six patients who underwent surgery for intracranial meningiomas (from 1998 to 2004) were investi-

*Corresponding author: Yves Denizot, UMR CNRS 6101, Faculté de Médecine, 2 rue Dr. Marcland, 87025 Limoges, France, Fax: (33) 555 4358 97; Tel: (33) 5554358 96; E-mail: yves.denizot@unilim.fr

Received February 01, 2010; Accepted February 25, 2010; Published February 25, 2010

Citation: De Armas R, Durand K, Weinbreck N, Robert S Jean-Jacques Moreau, et al. (2010) Genes Encoding Enzymatic Activities Implicated in the Eicosanoid Cascade of Arachidonic Acid and their Receptors are Expressed at mRNA Levels in Human Meningiomas. J Cancer Sci Ther 1: 003-007. doi:10.4172/1948-5956.1000015

Copyright: ( 2010 De Armas R, et al. This is an open-access article distributed under the terms of the Creative Commons Attribution License, which permits unrestricted use, distribution, and reproduction in any medium, provided the original author and source are credited.

J Cancer Sci Ther
Volume 2(1) : 003-007 (2010) - 003 
Citation: De Armas R, Durand K, Weinbreck N, Robert S Jean-Jacques Moreau, et al. (2010) Genes Encoding Enzymatic Activities Implicated in the Eicosanoid Cascade of Arachidonic Acid and their Receptors are Expressed at mRNA Levels in Human Meningiomas. J Cancer Sci Ther 1: 003-007. doi:10.4172/1948-5956.1000015

gated. Tumors were from the Service d'Anatomie Pathologique of the CHU Dupuytren (France). At the time of resection, tumor samples were fixed in $4 \%$ formalin, embedded in paraffin and sections were cut and stained with hemalum phloxine saffron. On paraffin sections, histological type and grade were determined according to the WHO classification (Louis et al., 2007). There were 15 grade I meningiomas including 7 transitional (2 man, 5 women, mean age 60 years), 3 meningothelial ( 1 man, 2 women, mean age 60 years) and 5 fibrous ( 5 women, mean age 59 years). Nine tumors were grade II meningiomas: 8 atypical (6 men, 2 woman, mean age 58 years) and 1 chordoid meningioma ( 1 man, 54 years) Two tumors were classified as anaplastic grade III meningiomas ( 2 men, mean age 54 years). After undergoing the routine hospital analysis, the excess of sample was kept at $-80^{\circ} \mathrm{C}$ until use and this in accordance with the regulations in force in France. No written or oral consent was obtained because it is a study of samples already collected and referred to research prior the French bioethical law (2004). Thus, ethics committee explicitly approved the waiver of consent. Normal meninges were not available in our institution in the light of our ethic committee law. The low amounts (10 - $15 \mathrm{mg}$ ) of available tumors only permitted investigations at the mRNA level.

\section{RNA isolation, reverse transcription and real time PCR analysis}

Total RNA was extracted using the "RNeasy Lipid Tissue mini kit" (Qiagen, Courtaboeuf, France). RNA integrity was checked by capillary electrophoresis on the Bioanalyzer 2100 (Agilent Technologies, Massy, France). Total RNA was reverse transcribed in single strand cDNA using random hexamers and as described in the protocol of the "SuperScript III First-Strand Synthesis System for RT-PCR" (Invitrogen, Cergy-Pontoise, France). Reactions were frozen at $-20^{\circ} \mathrm{C}$ until quantitative real time PCR
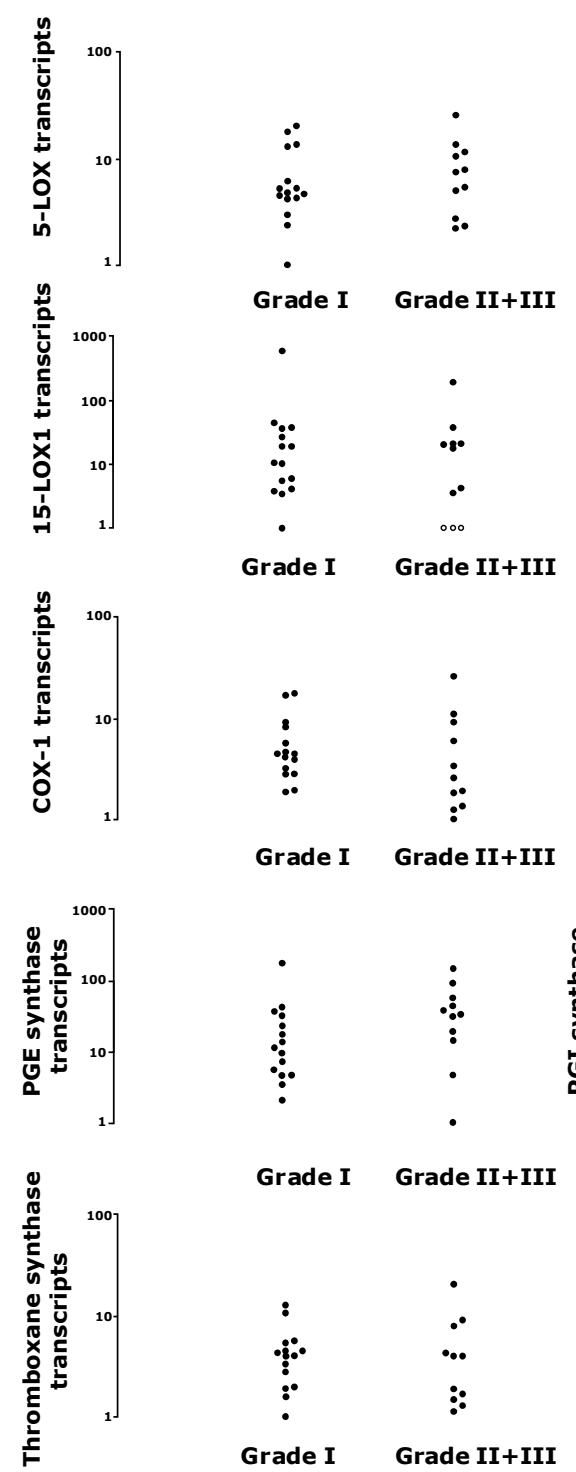

$\begin{array}{cc}\bullet & \vdots \\ \vdots & \vdots \\ \vdots & \vdots \\ \text { Grade I } & \text { Grade II+III }\end{array}$
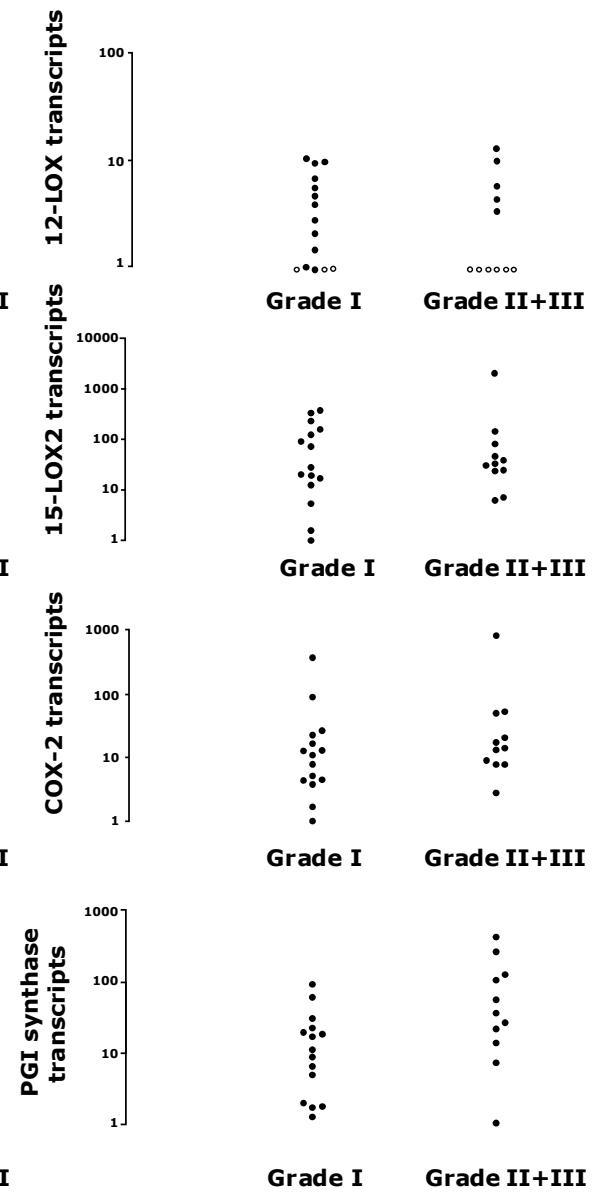

Figure 1: LOX and COX activities in human meningioma. Fifteen grade I and eleven grade II+III meningioma were investigated. Gene expression levels were normalized to 18S RNA (product reference: Hs99999901-s1). Amounts of transcripts were compared to sample with the lowest level of transcripts (a patient who was arbitrary quoted 1). (?) indicates patients with no detectable transcript. Significance was assessed by using the Kruskal-Wallis test followed by a Mann-Whitney $U$-test. No significant differences were documented between groups. Product references were the following: 5-LOX: Hs00386528-m1; 12S-LOX: Hs00167524-m1; 12R-LOX: Hs00153961m1; 15-LOX1: Hs00609608-m1; 15-LOX2: Hs00153988; COX-1: Hs00277289-s1; COX-2: Hs00153133-m1; PGE synthase: Hs01115610-m1; PGI synthase: Hs00168766-m1; TX synthase: Hs00233423-m1. 


\section{Journal of Cancer Science \& Therapy - Open Access \\ JCST/Vol.2 Issue 1}

realisation. PCR was performed in duplicate by using TaqMan assay reagents (Applied Biosystems, Foster City, CA) following the recommendations of the manufacturer. Amplification products were analyzed on an ABI Prism 7000 system (Applied Biosystems) (Fiancette et al., 2009; Vincent et al., 2009). Gene expression levels were normalized to $18 \mathrm{~S}$ RNA. Amounts of various transcripts were compared to sample with the lowest level of transcripts (a patient who was arbitrary quoted 1). The relative quantification of gene expression was performed using the "relative quantitation calculation and analysis software for Applied Biosystems real-time PCR systems".

\section{Statistical analysis}

Significance was assessed by using the Kruskal-Wallis test followed by a Mann-Whitney $U$ - test. A $\mathrm{p}<0.05$ was considered to be significant.

\section{Results and Discussion}

\section{LOX enzymatic transcripts in human meningiomas}

We firstly investigated if LOX genes were expressed in meningiomas. 12R-LOX transcripts were not present at detectable levels (data not shown). In contrast, 5-LOX, 12S-LOX, 15-LOX1 and 15 -LOX2 were detected in $100 \%, 65 \%, 88 \%$ and $100 \%$ of tumors, respectively (Figure 1). No difference was found for LOX transcripts amounts in relation to the tumor grade (Figure 1), nor the subtype of meningiomas, the presence of inflammatory infiltrated cells, of an associated edema, mitosis, brain invasion, vascularisation or necrosis (data not shown). The technique employed in this study allowed measurement of several mRNA in the same tumor. So it was possible to evaluate the levels of each of the isoforms relative to one another. Results indicated the following rank of magnitude in human meningiomas: 5 -LOX $>15$-LOX1 $>>15-L O X 2>12-L O X$. Results of the present study, thus, confirm the presence of 5-LOX in human meningiomas and that 5-LOX levels did not significantly differ among different WHO grades (Pfister et al., 2007). Beside 5LOX, we highlight for the first time the presence of 15-LOX and 12-LOX transcripts in meningiomas. The ability of 12-HETE and 15-HETE to regulate important functions of the immune system has been reported. They stimulate proinflammatory cytokine productions (Denizot et al., 1998; Denizot et al., 1999), indicating an ability of 12-HETE and 15-HETE to augment and prolong tissue inflammation. 12-LOX is found to regulate tumor angiogenesis (Hagmann, 1997). In contrast 15-LOX is a functional tumor suppressor that regulates differentiation, senescence and growth (Tang et al., 2007). The higher 15-LOX
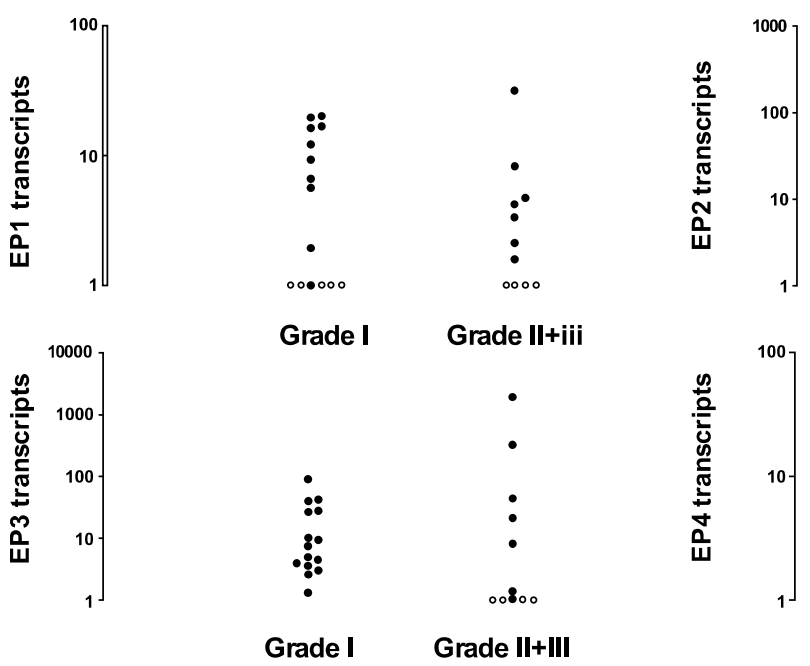

:•

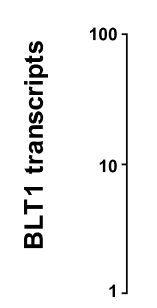

Grade I

Grade II+III

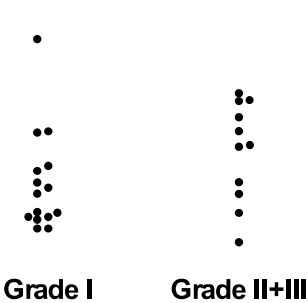

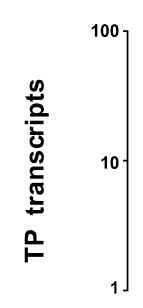

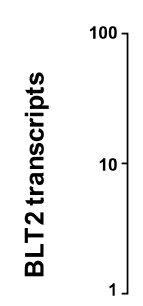

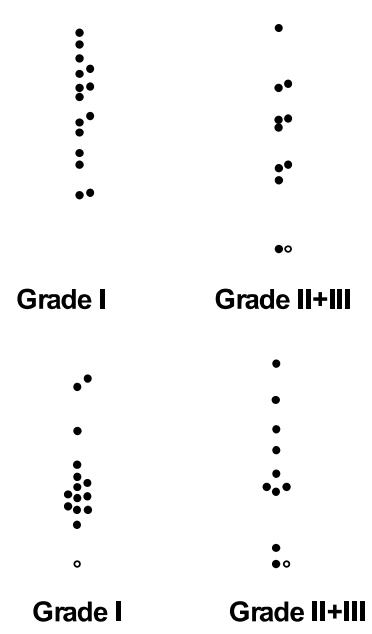

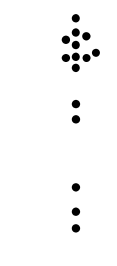

Grade I Grade II+III

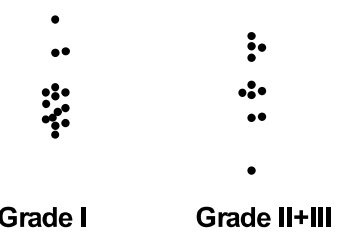

Figure 2: $\mathrm{LTB}_{4}$ and prostanoid receptors in human meningioma. Same legend as in Figure 1. Product references were the following: EP $: \mathrm{Hs}_{1} 00168752-\mathrm{m}_{1}$; EP Hs00168754-m1; EP 3 : Hs00168755-m1; EP $:$ Hs00168761-m1; IP: Hs00168765-m1; TP: Hs00169054-m1; BLT1: Hs00175124-m1; BLT2: Hs01885851-s1; 18S: Hs99999901-s1. 
Citation: De Armas R, Durand K, Weinbreck N, Robert S Jean-Jacques Moreau, et al. (2010) Genes Encoding Enzymatic Activities Implicated in the Eicosanoid Cascade of Arachidonic Acid and their Receptors are Expressed at mRNA Levels in Human Meningiomas. J Cancer Sci Ther 1: 003-007. doi:10.4172/1948-5956.1000015

expression as compared with 12-LOX one is in agreement with the slow growing and low metastatic status of meningioma tumors. Investigation of 12-LOX and 15-LOX transcripts in higher growth and metastatic brain tumors such as glioblastomas and astrocytomas would be of interest to reinforce this hypothesis.

\section{$\mathrm{LTB}_{4}$ receptor transcripts in meningiomas}

Reinforcing the putative role of 5-LOX in meningiomas, we found the presence of 5-LOX activating protein (FLAP) transcripts in $100 \%$ of meningioma samples (data not shown); FLAP functioning as a facilitator of 5-LOX activity (Radmark, 2002). We then investigated whether human meningioma tumors expressed $\mathrm{LTB}_{4}$ receptors. Transcripts for the two $\mathrm{LTB}_{4}$ receptors BLT1 and BLT2 were detected in $100 \%$ of human meningiomas (Figure 2). BLT1 and BLT2 play critical roles in host defense and in many inflammatory diseases by mediating the multiple activities of $\mathrm{LTB}_{4}$ (Tager et al., 2003). Considering the critical importance of the 5-LOX/FLAP/BLT1-BLT2 signal transduction pathway in carcinogenesis (Chen et al., 2006; Nie et al., 2000 ), its presence in meningiomas suggest its involvement in tumor growth. Together, these observations might suggest 5LOX inhibitors as an interesting target for drug development for meningioma therapy. However, given the ubiquitous expression of 5-LOX, drug targeting strategies must exhibit selectivity to avoid undesired side effects.

\section{COX enzymatic-related transcripts in human meningiomas}

In a second set of experiments we investigated enzymatic activities implicated in the COX cascade in meningiomas. COX1, COX2, PGE synthase, PGI synthase and TX synthase transcripts were detected in $100 \%$ of tumors (Figure 1). No difference ( $p>0.05$, Mann Whitney $U$-test) was found for COX and downstream enzymes in relation to the tumor grade (Figure 1) nor other clinical data (data not shown). Results indicated the following rank of magnitude for COX-related enzymatic activities: COX-1 > COX-2 and PGE synthase $>$ TX synthase $>$ PGI synthase. Results of the current study thus highlight an ubiquitous expression of COX-1 and COX-2 in meningiomas. $\mathrm{COX}$ isoforms function independently and play distinct roles in regulating AA metabolism. COX-1 is constitutively expressed and responsible for the low $\mathrm{COX}$ metabolite production required for cell homeostasis. In contrast COX-2 is produced during the course of inflammation, cellular stress and tumorigenesis in response to a wide range of stimuli (Bhattacharya et al., 1999). We did not find a relationship between COX-2 transcript levels and the tumor grade in meningiomas. This putative link remains a conflicting question since studies documented it (Pistolesi et al., 2007; Panagopoulos et al., 2008) while others did not (Linn et al., 2003; Buccoliero et al., 2007; Pfister et al., 2007). Nevertheless the ubiquitous expression of COX-2 in meningioma tumors may suggest considering COX-2 inhibitors as a potential area of therapeutic intervention. Thus, the COX-2 inhibitor celecoxib inhibits meningioma growth in vitro (Ragel et al., 2005) and reduces meningioma tumor growth in a mouse xenograft model (Ragel et al., 2007).

\section{Prostanoid receptor transcripts in human meningiomas}

Ubiquitous expression of PGE synthase, PGI synthase and TX synthase transcripts are found in meningiomas confirming their ability to produce $\mathrm{PGE}_{2}, \mathrm{PGI}_{2}$ and $\mathrm{TXA}_{2}$ (Castelli et al., 1989;
Constantini et al., 1993; Paoletti et al., 1989). These prostanoid metabolites are reported to play various roles in tumor progression and metastasis in several cancers (Wang et al., 2007). Reinforcing their putative roles in meningioma tumorigenesis, $\mathrm{EP}_{\mathrm{l}}$. ${ }_{4}$ IP and TP transcripts were documented in the vast majority of meningiomas $\left(65 \%, 96 \%, 80 \%, 92 \%, 96 \%\right.$ and $100 \%$ for $\mathrm{EP}_{1}$, $\mathrm{EP}_{2}, \mathrm{EP}_{3}, \mathrm{EP}_{4}$, IP and TP transcripts, respectively) but without link with the tumor grade (Figure 2). Results indicated the following rank of magnitude for prostanoid receptor transcripts: $\mathrm{EP}_{4}>\mathrm{EP}_{2}>\mathrm{EP}_{3}>\mathrm{EP}_{1}$ and $\mathrm{TP}>\mathrm{IP}$. $\mathrm{PGE}_{2}$ effects are mediated through interactions with four $\mathrm{G}$-protein coupled receptors. $\mathrm{EP}_{1}$ are coupled to $\mathrm{G}_{\mathrm{q} / \mathrm{p}}$ and ligand binding induces intracellular calcium level variations. $\mathrm{EP}_{2}$ and $\mathrm{EP}_{4}$ are coupled to $\mathrm{G}_{\mathrm{s}}$ and stimulate cAMP production while $\mathrm{EP}_{3}$ are coupled to $\mathrm{G}_{\mathrm{i}}$ and inhibit cAMP production (Bhattacharya et al., 1999; Harris et al., 2002). In meningiomas $\mathrm{PGE}_{2}$ might act via $\mathrm{EP}_{4}-\mathrm{EP}_{2}$ receptors, thus, through a cAMP-elevating effect. $\mathrm{PGE}_{2}$ is known to stimulate growth factor productions (Besse et al., 1999) thus acting on tumor progression by altering the tumor cytokine network. $\mathrm{PGI}_{2}$ (reported as an anticancer metabolite) and TXA 2 (reported as a procancer metabolite) have opposing actions and the balance between these two mediators is crucial. PGI $_{2}$ modulates platelet-vascular interactions and counteracts the proliferative and platelet effects of $\mathrm{TXA}_{2}$ in response to stress and injury (Cipollone et al., 2008).

\section{Concluding remarks}

In conclusion, genes encoding enzymatic activities implicated in the eicosanoid cascade are universally expressed in meningiomas. LOX- and COX-derived AA metabolites might act on tumor growth not only by acting directly on cell growth but also by altering the local cytokine and/or angiogenic networks. The potential role of theses COX- and LOX-derived metabolites on meningiomas is reinforced by the presence of $\mathrm{LTB}_{4}$ and prostanoid receptor transcripts in tumors. Further studies are needed to elucidate the precise contributions of each of these compounds in meningiomas and to determine their possible relevance in the targeting of new therapeutic interventions. As previously suggested for other tumors, 5-LOX and COX-2 appear as the most promising targets.

\section{References}

1. Besse A, Trimoreau F, Faucher JL, Praloran V, Denizot Y (1999) Prostaglandin E2 regulates macrophage-colony stimulating factor secretion by human bone marrow stromal cells. Biochim Biophys Acta 1450: 444-451. »CrossRef »PubMed » Google Scholar

2. Bhattacharya M, Verma DR, Chemtob S (1999) Nuclear prostaglandin receptors. Gene Ther Mol Biol 4: 323-338. »CrossRef » PubMed » Google Scholar

3. Boado R, Pardridge WM, Vinters HV, Black KL (1992) Differential expression of arachidonate 5-lipoxygenase transcripts in human brain tumors: evidence for the expression of a multitranscript family. Proc Nat Acad Sci USA 89:90449048. »CrossRef » PubMed » Google Scholar

4. Buccoliero AM, Castiglione F, Degl'Innocenti DR, Arganini L, Taddei A, et al (2007) Cyclooxygenase-2 (COX-2) overexpression in meningiomas: real time PCT and immunohistochemistry. Appl Immunohistochem Mol Morphol 15: $187-$ 192. »CrossRef » PubMed » Google Scholar

5. Castelli MG, Chiabrando C, Fanelli R, Martelli R, Butti G, et al. (1989) Prostaglandin and thromboxane synthesis by human intracranial tumors. Cancer Res 49: 1505-1508. »CrossRef » PubMed » Google Scholar

6. Chen X, Sood S, Yang CS, Li N, Sun Z (2006) Five-lipoxygenase pathway of 


\section{Journal of Cancer Science \& Therapy - Open Access JCST/Vol.2 Issue 1}

arachidonic acid metabolism in carcino-genesis and cancer chemoprevention. Current Cancer Drug Targets 6: 613-622. »CrossRef » PubMed » Google Scholar

7. Cipollone F, Cicolini G, Bucci M (2008) Cyclooxygenase and prostaglandin synthases in atherosclerosis: recent insights and future perspectives. Pharmacol Ther 118: 160-180. »CrossRef » PubMed » Google Scholar

8. Constantini S, Tamir J, Gomori MJ, Shohami E (1993) Tumor prostaglandin levels correlate with edema around supratentorial meningiomas. Neurosurgery 33: 204-210. »CrossRef » PubMed » Google Scholar

9. Denizot Y, De Armas R, Caire F, Pommepuy I, Truffinet V, et al. (2006) Platelet-activating factor and human meningiomas. Neuropathol App Neurobiol 32 674-678. »CrossRef » PubMed » Google Scholar

10. Denizot Y, Godard A, Raher S, Trimoreau F, Praloran V (1999) Lipid mediators modulate the synthesis of interleukin 8 by human bone marrow stromal cells. Cytokine 11: 606-610. »CrossRef » PubMed » Google Scholar

11. Denizot Y, Trimoreau F, Praloran V (1998) Effects of lipid mediators on the synthesis of leukemia inhibitory factor and interleukin 6 by human bone marrow stromal cells. Cytokine 10: 781-785. »CrossRef » PubMed » Google Scholar

12. Dupuis F, Desplat V, Praloran V, Denizot Y (1997a) Effect of lipidic mediators on the growth of human myeloid and erythroid progenitors. J Lipid Mediat Cell Signal 16: 117-125. » CrossRef » PubMed » Google Scholar

13. Dupuis F, Levasseur S, Jean-Louis F, Dulery C, Praloran V, et al. (1997b) Production, metabolism and effect of platelet-activating factor on the growth of the human K562 erythroid cell line. Biochim Biophys Acta 1359: 241-249.» CrossRef » PubMed » Google Scholar

14. Fiancette R, Vincent C, Donnard M, Bordessoule D, Turlure P, et al. (2009) Genes encoding multiples forms of phospholipase $\mathrm{A} 2$ are expressed in immature forms of human leukemic blasts. Leukemia 23: 1196-1199. »CrossRef » PubMed » Google Scholar

15. Hagmann W (1997) 12-lipoxygenase in human tumor cells. Pathol Oncol Res 3: 83-88. »CrossRef » PubMed » Google Scholar

16. Harris SC, Padilla J, Koumas L, Ray D, Phipps RP (2002) Prostaglandins as modulators of immunity. Trends Immunol 23: 144-150. »CrossRef " PubMed » Google Scholar

17. Kuhn H, Walther M, Kuban RJ (2002) Mammalian arachidonate 15 lipoxygenases Structure, function, and biological implications. Prostag Other Lipid Mediat 68-69: 263-290. »CrossRef » PubMed » Google Scholar

18. Lin CC, Kenyon L, Hyslop T, Hammond E, Andrews DW, et al. (2003) Cyclooxygenase-2 (COX-2) expression in human meningioma as function of tumor grade. Am J Clin Oncol 26: S98-102. »CrossRef » PubMed » Google Scholar

19. Louis DN, Oghaki H, Wiestler OD, Cavenee WK (2007) WHO classification of tumours of the central nervous system. Acta Neuropathol 114: 97-109. »CrossRef » PubMed » Google Scholar

20. Nathoo N, Barnett GH, Golubic M (2004) The eicosanoid cascade: possible role in gliomas and meningiomas. J Clin Pathol 57: 6-13. »CrossRef » PubMed » Google Scholar

21.Nie D, Tang K, Szekeres K, Li L, Honn KV (2000) Eicosanoid regulation of angiogenesis in human prostate carcinoma and its therapeutic implications. Ann New York Acad Sci 905: 165-176. »CrossRef » PubMed » Google Scholar

22. Panagopoulos AT, Lancellotti CL, Veiga JC, de Aguiar PH, Colquhoun A(2008) Expression of cell adhesion proteins and proteins related to angiogenesis and fatty acid metabolism in benign, atypical, and anaplastic meningiomas. $\mathrm{J}$ Neurooncol 89: 73-87. »CrossRef » PubMed » Google Scholar

23. Paoletti P, Chiabrando C, Gaetani P, Castelli MG, Butti G, et al. (1989) Prostaglandins in human brain tumors. J Neurosurg Sci 33: 65-69. »CrossRef » PubMed » Google Scholar

24. Pfister C, Ritz R, Pfrommer H, Bornemann A, Tatagiba MS, et al. (2007) Are there attacking points in the eicosanoid cascade for chemotherapeutic options in benign meningiomas? Neurosurg Focus 23: E8. »CrossRef »PubMed » Google Scholar

25. Pistolesi S, Boldrini L, Gisfredi S, Ursino S, Ali G, et al. (2007) Expression of cyclooxygenase-2 and its correlation with vasogenic brain edema in human intracranial meningiomas. Cancer Invest 18: 1-8. »CrossRef » PubMed » Google Scholar

26. Radmark O (2002) Arachidonate 5-lipoxygenase. Prostag Other Lipid Mediat 68- 69: 211-234. »CrossRef » PubMed » Google Scholar

27. Ragel BT, Jensen RL, Gillespie DL, Prescott SM, Couldwell WT (2007) Celecoxib inhibits meningioma tumor growth in a mouse xenograft model. Cancer 109: 588-597. » CrossRef » PubMed » Google Scholar

28. Ragel BT, Jensen RL, Gillespie DL, Prescott SM, Couldwell WT (2005) Ubiquitous expression of cyclooxygenase- 2 in meningiomas and decrease in cell growth following in vitro treatment with the inhibitor celecoxib: potential therapeutic application. J Neurosurg 103: 508-517. »CrossRef » PubMed » Google Scholar

29. Tager AM, Luster AD (2003) BLT1 and BLT2: the leukotriene B4 receptors Prostag Leuk Ess Fatty Acids 69: 123-134. »CrossRef » PubMed » Google Scholar

30. Tang DG, Bhatia B, Tang S, Schneider-Broussard R (2007) 15-lipoxygenase 2 (15-LOX2) is a functional tumor suppressor that regulates human prostate epithelial cell differentiation, senescence, and growth (size). Prostag Other Lipid Mediat 82: 135-146. »CrossRef » PubMed » Google Scholar

31. Vincent C, Fiancette R, Donnard M, Bordessoule D, Turlure P, et al. (2009) 5 LOX, 12-LOX and 15-LOX in immature forms of human leukemic blasts. Leukemia Res 32: 1756-1762. »CrossRef » PubMed » Google Scholar

32. Wang MT, Honn KV, Nie D (2007) Cyclooxygenases, prostanoids, and tumor progression. Cancer Met Rev 26: 525-534. »CrossRef » PubMed » Google Scholar

33. Whittle IR, Smith C, Navoo N, Collie D (2004) Meningiomas. Lancet 363: 1535-1543. »CrossRef » PubMed » Google Scholar

34. Yoshimoto T, Takahashi Y (2002) Arachidonate 12-lipoxygenases. Prostag Other Lipid Mediat 68-69: 245-262. »CrossRef » PubMed » Google Scholar 